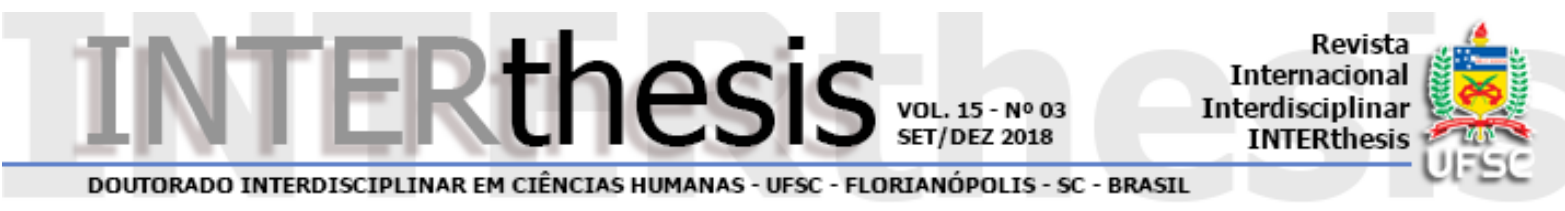

\title{
O CORPO SEXUADO NAS RELAÇÕES DE PODER
}

Paulo Roberto de Carvalho1

\section{Resumo}

Em Foucault, a problemática do poder comparece sempre referida à materialidade do corpo, às suas características e potencialidades. Com a noção de poder disciplinar, ele assinala uma vertente individualizante do poder, que atua nos corpos tendo como objetivo torná-los úteis e dóceis. Foucault também coloca em evidência um poder que se exerce sobre a população (a biopolítica), que reconhece a coletividade e intervém sobre ela, especificamente sobre sua condição corporal . A partir dos referenciais acima descritos, este estudo tem por objetivo analisar a trajetória de crescente politização das temáticas ligadas ao corpo e à sexualidade que ganharam destaque ao longo do século XX e que, de modo parcial, foram incorporadas ao debate cotidiano das populações. Do ponto de vista metodológico, trata-se de estudo teórico e qualitativo que reúne subsídios para a análise da presença recorrente das tematícas corporais nos diferentes contextos da contemporaneidade. Dentre os resultados obtidos tem-se que as características classificatórias do corpo humano vivo, tais como gênero, sexualidade e faixa etária tornaram-se alvo de uma atenção permanente, seja na forma de produção de conhecimento sobre as mesmas ou ainda como objeto de uma sensibilização que toma o corpo em sua dimensão política inscrevendo-o, a partir daí, nas políticas institucionalizadas e nas legislações. Como conclusão parcial chegase à constatação de que está em curso uma mudança normativa e valorativa de amplo alcance que tem na questão do corpo sexuado seu eixo principal.

Palavras-chave: Biopolítica. Corpo. Poder. Sexualidade. Subjetividade.

\section{INTRODUÇÃO}

A produção teórica de Michel Foucault, em diferentes períodos, manteve-se comprometida com a investigação de um objeto complexo e de difícil visualização: as relações de poder. Suas obras dedicaram-se, de modo incisivo e continuado, a descrever o poder, caracterizando-o a partir dos efeitos que produz sobre a vida humana, individual e coletiva e evidenciando sua incontornável presença nas relações sociais. O poder, tal como exposto por Foucault é um objeto histórico, ou

\footnotetext{
1 Doutor em Psicologia Clínica pela Pontifícia Universidade Católica de São Paulo. Docente do Programa de Pós-Graduação em Psicologia e do Departamento de Psicologia Social e Institucional da Universidade Estadual de Londrina, Londrina, PR, Brasil E-mail: paulor@uel.br
} 
seja, varia através dos tempos nos seus modos de efetuação, mas também em função do contexto social no qual se exerce. Ainda que possa variar, as relações de poder mantiveram-se constantes nos períodos descritos pelo autor, produzindo efeitos sociais que convergem em direção a determinadas finalidades: fazer dos corpos humanos e da vida dos homens algo de que se possa extrair valor regularmente. Assim, o poder mantém-se estável no que diz respeito à sua presença e efetuação, bem como com relação aos seus objetivos. Ao caracterizar o percurso teórico adotado por Foucault Machado considera:

Objetivo ao mesmo tempo econômico e político: aumento do efeito de seu trabalho, isto é, tornar os homens força de trabalho dando-lhes utilidade econômica máxima; diminuição de sua capacidade de revolta, de resistência, de luta, de insurreição contra as ordens do poder, neutralização dos efeitos de contra-poder, isto é, tornar os homens dóceis politicamente. Portanto, aumentar a utilidade econômica e diminuir os inconvenientes, os perigos políticos: aumentar a força econômica e diminuir a força política (MACHADO, 1996, p. xvi).

Foucault, por sua vez, elege uma perspectiva ou ainda uma abordagem estrategicamente posicionada, que orienta suas pesquisas. A produção do conhecimento sobre o poder comparece então como mais um instrumento na luta contra esse mesmo poder, resgatando assim o caráter político da produção teórica. $O$ campo das relações de poder é marcado, assim, por uma reversibilidade permanente, onde poder e resistência confrontam-se permanentemente, o que pode ser caracterizado como um enfrentamento nas relações de poder. $O$ autor considera ainda que o poder é, antes de qualquer coisa, uma relação de forças que se estabelece no meio social. Nas suas palavras, é necessário fazer a

Luta contra o poder, luta para fazê-lo aparecer e ferí-lo onde ele é mais invisível e mais insidioso. Luta não para uma 'tomada de consciência' [...], mas para destruição progressiva e a tomada do poder ao lado de todos que lutam por ela, e não na retaguarda, para esclarecê-los. Uma 'teoria' é o sistema regional desta luta (FOUCAULT, 1984, p. 71).

A constatação de que a vida em sociedade é permanentemente atravessada pelas relações de poder vai se consolidando apesar de uma dificuldade já assinalada: o poder é invisível, uma vez que se faz presente nas relações sociais, não se separando delas. Para Foucault, no entanto, o alvo das relações de poder, seu espaço de efetuação, onde ele se mostra e se manifesta, não tem nada de oculto ou invisível. Trata-se da vida humana na sua materialidade constituinte, ou seja, dos corpos humanos que a ordem social capitalista pretende utilizar e deles extrair valor. Vejamos: "Na verdade, nada é mais material, nada é mais físico, mais corporal que o 
exercício do poder... Qual é o tipo de investimento do corpo que é necessário e suficiente ao funcionamento de uma sociedade capitalista como a nossa?" (Idem, p. 147). Assim, é a relação entre o corpo humano, dotado de características singulares, e a ordem socioeconômica que é colocada em questão. Trata-se então de assinalar uma inscrição gradual no ordenamento social que avança sobre diferentes aspectos da vida biológica e social do humano.

A sexualidade comparece como um destes campos submetidos aos processos de normalização efetuados no âmbito das relações de poder. É possível sistematizar uma série de questões que hoje aglutinam sujeitos em ações comuns cujo eixo corresponde à questão do corpo nas suas diferentes dimensões, tais como gênero, sexualidade, faixa etária, hábitos e costumes. Resulta daí a compreensão da emergência da tematica corporal nos diferentes contextos da vida em sociedade. De modo geral, pode-se dizer que, por efeito da normalização da sexualidade nas denominadas sociedades ocidentais, o sexo ganhou evidência na vida cotidiana de todos os segmentos sociais, tornando-se cada vez mais um objeto de atenção coletiva. Cabe destacar sua presença recorrente nos meios de comunicação (MALUF; CARVALHO, 2018) e, como veremos adiante, nos processos educacionais.

Metodologicamente, cabe considerar que se trata de um estudo teórico e qualitativo que tem por objetivo fazer um levantamento dos autores que evidenciaram a ascensão das questões relativas ao corpo na produção do conhecimento, na vida cotidiana e no âmbito das legislações. Para tanto foram selecionados autores que desdobraram a temática do corpo e da sexualidade em um conjunto de problemáticas específicas, evocando uma perspectiva teórica e epistemológica voltada para o estudo da diferença e do questionamento das universalidades, como é o caso de Michel Foucault.

De modo complementar e integrado, o presente estudo se desenvolve em dois níveis: Primeiramente, no que diz respeito à problemática da relação entre o sexo e o poder, são consideradas algumas obras de Michel Foucault (1984; 1988; 2014) como ponto de partida e referencial de análise. No segundo momento, adotar-se a concepção de corpo sexuado para ampliar o raio de análise e assim problematizar uma série de temas diretamente relacionados. Com os estudos de Pelbart (2013), Agamben (2002), Donzelot (1986) e Caliman (2012) analisam-se os regimes de poder que se exercem sobre os aglomerados populacionais, as multidões de corpos vivos. Já a partir dos escritos de Silva (2015) e Sant'Anna (2014), a questão do corpo 
sexuado inscrito na linha do tempo é abordada, com suas fases de desenvolvimento e na valorização estética. Por fim, serão utilizados autores (CARVALHAES; MANSANO, 2016) que estendem a problematização sobre o corpo sexuado para as potências políticas do agir, bem como para o campo da saúde (LEMOS et al, 2016).

Esta investigação justifica-se, assim, pela necessidade de uma compreensão crítica do tempo histórico em que vivemos no que diz respeito às transformações políticas, institucionais e consuetudinárias disparadas a partir da atenção crescente voltada para condição corporal que as sociedades experimentaram em particular no século XX. No decorrer do mesmo, assistiu-se a uma ascensão do debate sobre um conjunto de temas referidos ao corpo que prefigurou a inscrição gradativa dos mesmos em diferentes domínios do meio social. Quanto à sexualidade, mantida à parte da discussão aberta por longo período, operou-se uma completa inversão: nos espaços públicos tanto quanto na vida privada, o discurso sobre o sexo veio para ficar. Compreender tais mudanças de modo a fundamentar as intervenções sobre a temática do corpo na contemporaneidade é, de fato, um imperativo.

\section{CORPO EM QUESTÃO}

Na vertente histórica da análise das relações de poder proposta por Foucault é possível encontrar uma afirmação surpreendente: o poder, dirigido por um longo período para a condição corporal, produziu um efeito propriamente populacional tornando os humanos sensíveis a seus próprios corpos, desenvolvendo uma atenção coletiva para os mesmos, algo que se faz historicamente presente desde a consolidação da formação social capitalista. Ou ainda, como ele considera: "Eu penso que, do século XVII ao início do século XX, acreditou-se que o investimento do corpo pelo poder deveria ser denso, rígido, constante, meticuloso" (FOUCAULT, 1984, p. 147).

A gama de efeitos decorrentes de uma intencionalidade dirigida dos poderes para os corpos é bastante ampla e se distribui sobre todo o tecido social. Por um lado é possível identificar os efeitos objetivos, por exemplo, na multiplicação dos cuidados e práticas de adestramento do corpo. Por outro lado produzem-se efeitos subjetivos, na forma de desejo, vivido por esses humanos sensibilizados pelo poder, desejo este que passa a compor a subjetividade das populações. É o que pode se observar na passagem que se segue: 
O domínio, a consciência de seu próprio corpo só puderam ser adquiridos pelo efeito do investimento do corpo pelo poder: a ginástica, os exercícios, o desenvolvimento muscular, a nudez, a exaltação do belo corpo... Tudo isso conduz ao desejo de seu próprio corpo através de um trabalho insistente, obstinado, meticuloso, que o poder exerceu sobre o corpo das crianças, dos soldados, sobre o corpo sadio (FOUCAULT, 1984, p. 146).

É nesse contexto que a investigação sobre o poder depara-se com um dado novo, um componente outro que a partir de então será incorporado na analítica das relações de poder: a constatação de que onde o poder se exerce, em função de sua presença, emerge uma resistência. No caso desta atenção dirigida ao corpo, um dos efeitos bastante visíveis da relação entre poder e resistência se evidencia: trata-se de aceitar ou de resistir às finalidades implícitas de todo processo, ou seja, à inscrição completa dos corpos humanos no mundo do trabalho. Na descrição de Foucault:

\begin{abstract}
Mas, a partir do momento em que o poder produziu este efeito, como consequência direta de suas conquistas, emerge inevitavelmente a reivindicação de seu próprio corpo contra o poder, a saúde contra a economia, o prazer contra as normas morais da sexualidade, do casamento, do pudor. E, assim, o que tornava forte o poder passa a ser aquilo por que ele é atacado... O poder penetrou no corpo, encontra-se exposto no próprio corpo... (FOUCAULT, 1984, p. 146).
\end{abstract}

O que ganha relevo neste percurso é uma tensão continuada que atravessa a produção teórica do autor: assinalar, por um lado, os processos históricos de longo curso tais como a sensibilização da condição corporal operada pelos poderes sobre as populações ao longo de quase três séculos; e, por outro, utilizar-se deste mesmo percurso para construir um olhar analítico capaz de reconhecer uma inteligibilidade na vida humana administrada pelo poder no presente. Em outras palavras, Foucault detém-se sobre aquilo que efetivamente acontece na atualidade, na constituição do humano datado do periodo histórico em que vivemos. A intenção de utilizar abordagem histórica para a decifração do presente fica evidente no fragmento que se segue:

Acho que, desde o século XIX, a filosofia não parou de se aproximar da questão: 'O que acontece atualmente e o que somos nós, nós que talvez não sejamos nada mais e nada além daquilo que acontece atualmente?' A questão da filosofia é a questão deste presente que é o que somos. Daí a filosofia hoje ser inteiramente política e inteiramente indispensável à política (FOUCAULT, 1984, p. 239).

Se na concepção de Foucault a filosofia é uma tarefa eminentemente política, é porque também ela se produz no contexto das relações de poder, constituindo-se num domínio do saber que dá suporte ao exercício dos poderes. Aos poderes que investiram o adestramento dos corpos de modo contínuo, proporcionando aquisição 
de habilidades para serem posteriormente aproveitadas, Foucault propôs a denominação de poderes disciplinares, colocando em destaque o caráter individualizante de seus procedimentos. Mas, seria a vertente do poder disciplinar a única a participar da produção histórica da a atenção coletiva dirigida ao corpo? Ou haveria outros procedimentos decorrentes do poder também presentes na atualidade? Somente formulando esse tipo de questão aproximamo-nos daquilo que Foucault denominava "o verdadeiro trabalho, o do historiador do presente" (Idem, p. 239).

Há que se considerar que o exercício dos poderes sobre os corpos possibilitou a criação de um leque de saberes, também sobre os mesmos, assim como sobre as especificidades desta condição que é a do ser vivo. Os saberes acumulados sobre a condição humana ganham, no entanto, um outro enfoque, diferente daquele dado pelos poderes disciplinares, que tomavam o sujeito como alvo individualizado de uma intervenção moduladora. A vida humana passa a ser considerada também na sua dimensão coletiva, populacional e, como tal, será objeto de intervenções que objetivam sua regulamentação. Ganha contorno, assim, uma segunda vertente dos poderes, agora dirigida sobre a especificidade do vivo, que vive coletivamente. Foucault denominou-a biopolítica. Analisando a emergência desta vertente na obra de Foucault, Pelbart considera que:

\begin{abstract}
a biopolítica, surge no século seguinte e mobiliza um outro componente estratégico, a saber, a gestão da vida incidindo já não sobre os indivíduos, mas sobre a população enquanto população, enquanto espécie. Está centrada não mais no corpo-máquina, porém no corpo-espécie - é o corpo atravessado pela mecânica do vivente, suporte de processos biológicos: a proliferação, os nascimentos e a mortalidade, o nível de saúde, a longevidade - é a biopolítica da população (PELBART, 2003, p. 57).
\end{abstract}

A biopolítica configura-se, então, como um emergente histórico, um processo que comporta a descoberta gradativa do humano como matéria viva sobre a qual o poder se exerce.Ela evidencia também um direcionamento nas relações de poder,que buscam maximizar a vida humana para dela extrair valor. Constrói-se, assim, um olhar voltado para a singularidade do vivo, para tudo o que lhe é inerente, bem como para aquilo que condiciona sua existência. Foucault detém-se no assinalamento dessa emergência, colocando em destaque aquilo que a define nos termos das relações de poder: o ingresso do vivo nos cálculos e procedimentos do poder e o modo que este se propõe a gerir a vida, otimizando sua duração e capacitação e criando assim as condições mais adequadas para se operar a extração de valor da mesma. Ou ainda, como o autor considera: 
O homem ocidental aprende pouco a pouco o que é ser uma espécie viva num mundo vivo, ter um corpo, condições de existência, probabilidade de vida, saúde individual e coletiva, forças que se podem modificar, e um espaço em que se pode reparti-las de modo ótimo. Pela primeira vez na história, sem dúvida, o biológico reflete-se no político; o fato de viver não é mais este sustentáculo inacessível que só emerge de tempos em tempos, no acaso da morte e de sua fatalidade: cai, em parte, no campo de controle do saber e de intervenção do poder (FOUCAULT, 1988, p. 134).

Uma vez considerada a biopolítica como uma das vertentes dos poderes que incide sobre a vida humana, chega-se à constatação de que dois dispositivos distintos do poder (o disciplinar e a biopolítica) operaram em planos distintos ao longo do século XX investindo e transformando o corpo individual assim como as populações. Cada um desses dispositivos produz seu próprio campo de saberes, bem como os procedimentos de intervenção deles decorrentes.

A noção de biopoder, proposta por Pelbart, toma conjuntamente essas duas vertentes, demonstrando que o dispositivo do poder pode se encarregar da vida humana ao mesmo tempo individual e coletivamente. Nas palavras de Pelbart é possível entrever a amplitude e a complexidade que o biopoder adquire na tarefa de administrar a vida humana,tornando-a cada vez mais útil para o ordenamento social:

\begin{abstract}
Daí uma tecnologia de dupla face a caracterizar o biopoder: por um lado as disciplinas, as regulações, a anatomo-política do corpo, por outro, a biopolítica da população, a espécie, as performances do corpo, os processos da vida - é o modo que tem o poder de investir a vida de ponta a ponta. Ao lado do sujeitamento dos corpos através das escolas, colégios, casernas, ateliês, surgem os problemas de natalidade, longevidade, saúde pública, habitação, imigração. Ainda separadas no início, a disciplinarização dos corpos e a regulação da população acabam confluindo (PELBART, 2003, p. $57)$.
\end{abstract}

Ocorre, no entanto, que das múltiplas características desse corpo vivo que o poder busca controlar e extrair valor, uma delas ganha destaque e acaba sendo sobreinvestida justamente porque se encontra no cruzamento das duas vertentes do poder, a disciplinar e a biopolítica. Trata-se da sexualidade que comparece simultaneamente em ambas as vertentes e torna-se objeto de atenção por parte de diferentes saberes bem como dos poderes vigentes. Em função desta evidência que a sexualidade ganha, a polêmica e a politização se fazem cada vez mais presentes em torno dela. Vejamos:

Sobre tal pano de fundo, pode-se compreender a importância assumida pelo sexo como foco de disputa política. É que ele se encontra na articulação entre os dois eixos ao longo dos quais se desenvolveu toda tecnologia política da vida. De um lado, faz parte das disciplinas do corpo: adestramento, intensificação e distribuição das forças, ajustamento e economia das energias. Do outro, o sexo pertence à regulação das populações, por todos os efeitos globais que induz (FOUCAULT, 1988, p. 136). 
Este é o fato que merece destaque quando efetuamos uma abordagem histórica voltada para o período atual. O corpo, em trajetória ascendente, é tematizado cada vez mais na política, na educação, na arte e na vida cotidiana. É precisamoente isso que será problematizado na próxima seção.

\section{O CORPO COMO FOCO DE DISPUTA POLÍTICA}

Com os elementos assinalados, torna-se possível delinear um diagnóstico parcial da contemporaneidade capitalística. Um dos aspectos relevantes nessa direção foi diretamente enunciado por Foucault: o sexo está colocado num processo ascendente de disputa política, ele é o campo onde diferentes posições se confrontam. Porém, se está de fato em curso uma politização da sexualidade, ela está relacionada com o investimento sistemático que os poderes realizaram sobre o corpo sexuado. Assim, num nível mais amplo que é o da condição corporal esta ascensão da polêmica e da politização também se faz. De modo que o sexo em particular, mas toda condição corporal num sentido mais amplo, encontram-se em um processo de politização crescente cujos efeitos se distribuem sobre o meio social na contemporaneidade. Este é o contexto diagnosticado por Foucault e que, nas décadas que se seguiram à sua morte, somente se fez mais presente. Foucault chega ao ponto de dizer que as sociedades contemporâneas podem ser denominadas como sendo "da sexualidade". Nas suas palavras:

Quanto a nós, estamos em uma sociedade do 'sexo', ou melhor, 'de sexualidade': os mecanismos de poder se dirigem ao corpo e à vida, ao que faz proliferar, ao que reforça a espécie, seu vigor, sua capacidade de dominar, ou sua aptidão para ser utilizada. Saúde, progenitura, raça, futuro da espécie, vitalidade do corpo social, o poder fala da sexualidade e para a sexualidade; quanto a esta, não é marca ou símbolo, é objeto e alvo (FOUCAULT, 1988. p. 138).

Eis, então, o que chama a atenção no olhar de Foucault sobre o contemporâneo e que dirige sua investigação: "busco as razões pelas quais a sexualidade, longe de ter sido reprimida na sociedade contemporânea, está, ao contrário, sendo permanentemente suscitada" (IDEM, p. 139).

Em princípio, duas direções possíveis podem ser consideradas para politização contemporânea em torno da sexualidade e do corpo: na primeira delas, trata-se de reconhecer, nas lutas que se articulam em torno do corpo sexuado, um efeito direto, um resultado decorrente dos procedimentos do poder. Foucault investigou esta 
possibilidade: "E suponhamos que os mecanismos de poder foram, de fato, mais empregados para suscitar e 'irritar' a sexualidade" (IDEM, p. 141).

Outra direção a ser considerada é que a existência do poder é inseparável dos processos de resistência que se mobilizam, na forma de contra-poderes, opondo-se estrategicamente a ele. Seguindo esta perspectiva é possível considerar: "A cada movimento de um dos dois adversários corresponde o movimento do outro" (FOUCAULT, 1984, p. 147). De qualquer forma, como efetuação do poder ou como resistência voltada contra ele, a atualidade, aproximadamente três décadas depois da morte do Foucault, assiste a multiplicação das lutas em torno do corpo e do sexo. Um campo complexo e multifacetado de temáticas emerge, sendo que estas se tornam polos aglutinadores de novos movimentos sociais organizados em torno da corporeidade. A sexualidade mantém-se em destaque com uma proliferação das lutas de gênero, mas também nas lutas em torno das faixas etárias e da morte (SILVA, 2015). Todas as dimensões da existência que estão referidas à trajetória do corpo vivo ganham politização. É o que se observa na ascensão da polêmica em torno da eutanásia e do suicídio. Questões adjacentes à corporeidade tais como a estética corporal e a indumentária experimentam um movimento similar de politização crescente. Em qualquer desses casos, assim como em outros, cabe observar que já não se trata de sujeitos individuais falando de seus corpos sexuados sob o recorte da vida privada, mas sim de uma nova realidade enunciada por Foucault. Mas, o que caracteriza este momento emergente? Em princípio trata-se de um movimento que incorpora de socialização do corpo, tal como observa Pelbart, comentando a obra foucaultiana: "pois a vida a mais 'privada' tornou-se imediatamente 'política', na esteira da definição original de Foucault sobre a biopolítica como 'socialização' do corpo, num sentido agora alargado" (PELBART, 2003, p. 66).

A emergência de uma socialização dos corpos, inclusive no que diz respeito à sexualidade, lança alguma inteligibilidade em uma série de fatos da vida cotidiana atual. Numa aproximação preliminar pode-se considerar que a separação entre a vida pública e privada, traço constituinte da organização das sociedades na primeira metade do século $X X$, é atacada uma vez que o sexo era mantido na esfera exclusiva do privado. Com o deslocamento gradativo do mesmo para a esfera pública, ou para o meio social, a produção dos saberes sobre o corpo sexuado experimenta um crescimento que, no entendimento de Foucault, chega a surpreender: "Creio que a cultura ocidental foi surpreendida por uma espécie de desenvolvimento, de hiper- 
desenvolvimento do discurso da sexualidade, da teoria da sexualidade, da ciência da sexualidade, do saber sobre a sexualidade" (FOUCAULT, 2004, p. 58).

Dentre as diferentes efetuações do poder que coloca em destaque a sexualidade pode-se assinalar, pelo seu caráter emblemático, a adoção de políticas públicas que oficializaram a presença da educação sexual ao longo do século XX nas sociedades capitalistas. De fato, ao colocar a sexualidade em discussão no espaço público da instituição escolar, as sociedades admitiram um movimento em direção à socialização do corpo, criando condições para difusão de saberes sobre os corpos sexuados ao mesmo tempo que incitavam os alunos a discutir o tema. Foram ensaiadas formas de resistência que, no entanto, resultaram infrutíferas (DONZELOT, 1986).

Os saberes sobre a sexualidade e o corpo, por sua vez, ao serem colocados em circulação, tiveram por efeito ampliar cada vez mais a interlocução e a atenção coletiva sobre o sexo, chamando a atenção para o mesmo. Seguindo a mesma vertente, será, no entanto, o corpo enquanto ser biológico e não somente o sexo que se tornará uma referência obrigatória para a análise política dos contextos sociais no século XX. Para Agamben, com o advento da biopolítica, "a vida biológica, com as suas necessidades, tornara-se por toda parte o fato politicamente decisivo" (AGAMBEN, 2002, p. 127).

O conjunto de efeitos produzidos pelos dispositivos de poder quando passaram a se acercar do corpo sexuado ou ainda da condição biológica (que condensa indivíduo e espécie) é bastante extenso e em muitos aspectos não conhecido. Cabe destacar, preliminarmente, um efeito mais evidente, disseminado no meio social. Um efeito de legitimação, de atos e palavras, mas também do percurso, pregresso e futuro, que os sujeitos adotam ao longo da vida:

\footnotetext{
Nosso sofrimento psíquico, nossos medos, angústias, comportamentos e emoções, sejam eles normais ou anormais, devem, necessariamente, ter origem e causa biológica, caso queiram ser considerados reais e legítimos. É neste sentido que as pessoas estão descrevendo a si e aos outros através de uma linguagem somática. O corpo, quase sempre reduzido ao cérebro, está no centro das explicações sobre quem somos, sobre quem fomos e sobre o que seremos (CALIMAN, 2012, p. 115).
}

Que uma série de sentimentos e percepções corporais ganhe legitimidade pela via da identificação de uma causalidade biológica chega a ser compreensível, posto que são manifestações que ocorrem no corpo vivo. Sintomaticamente, no entanto, questões de natureza social, referidas aos modos de vida coletivamente 
compartilhados também passam, na atualidade, a buscar sua legitimação nos marcos das ciências biológicas. É nesse ponto que a expressão "biopolítica" ganha visibilidade maior. Nas palavras de Caliman "ingressamos numa era em que a própria cidadania vai buscar fundamentos na biologia, caracterizando-se como "cidadanias biológicas"” (CALIMAN, 2012, p. 113).

À medida que o campo político e social passa a tomar o corpo vivo e sexuado como referência, o dispositivo biopolítico amplia significativamente seu raio de atuação em um processo que torna a condição corporal um elemento articulador das novas formas de controle. Tal como observam Lemos, Galindo, Rodrigues e Aguiar (2016, p. 188), o "controle biotecnológico das cidades e dos corpos, ganha intensa materialidade pela medicina social, que se estende por toda a sociedade, como racionalidade reducionista da complexidade da vida aos aspectos biomédicos".

De modo gradativo, as problemáticas referidas ao corpo vivo, depois de sensibilizarem contingentes populacionais ganham uma amplitude ainda maior no meio acadêmico tornando-se objeto de investigação científica , de modo sistemático. Os estudos sobre o corpo (MANSANO, 2016; SANT'ANNA, 2014) desdobram-se em diferentes direções, ganhando destaque a problemática da potência afetiva do agir, incluíndo o afetar e o ser afetado pelos encontros.

O ingresso sistemático das questões referidas ao corpo na política institucionalizada também pode ser relacionado com a sensibilização em escala populacional para as problemáticas da condição corporal. As lutas políticas e institucionais em torno do corpo ganharam um contorno definido: inscrever nos marcos legais das sociedades ocidentais uma série de reinvindicações e posicionamentos que buscam o aparo legal para as diferentes condições do corpo. As diferentes configurações da condição corporal passam a ser objeto de uma normatização. Ganham evidência os marcos legais específicos dirigidos para problemáticas como o gênero, a sexualidade e as faixas etárias (JIMENEZ; ASSIS; NEVES, 2015).

Também entram na cena da política instituída as lutas das mulheres, em especial na segunda metade do século XX, que se desdobram em diferentes tidpos de reinvindicação (CARVALHAES; MANSANO, 2016). São legislações que tematizam a proporcionalidade de gênero na representação política, a criminalização de práticas preconceituosas e da violência de gênero, dentre várias outras. 
A atenção crescente dirigida ao corpo sexuado em diferentes áreas, tais como a saúde, a educação e o campo jurídico-legal, consolidou no meio acadêmico, ao longo de todo século $X X$, os denominados estudos de gênero voltados para singularidades e variações dos corpos sexuados (BUTLER, 2003; HARAWAY, 1995). Mulheres e homens passaram a ser objeto de investigação sistemática nas condições de heterossexuais, homossexuais, bissexuais e transsexuais. Um campo vasto de pesquisa se consolidou nessa direção e não cessa de expandir-se, abarcando hoje o estudo sobre temas limítrofes tais como a assexualidade. Simultaneamente à presença recorrente dos estudos de gênero, as questões do corpo sexuado ganham visibilidade no meio social, gerando a mobilização e atuação de coletivos cada vez maiores. Com pautas reivindicatórias dirigidas ao menos para dois grandes objetivos de natureza política: por um lado, garantir às denominadas minorias sexuais os mesmos direitos e prerrogativas dos corpos sexuados; por outro, produzir uma mudança valorativa e nos costumes que se estenda a todo meio social e que inclua as variantes do corpo sexuado.

A questão da homossexualidade, por sua vez, vai ganhar um destaque significativo com o reconhecimento das uniões entre pessoas do mesmo sexo no ordenamento jurídico de vários países do mundo. Assim, de modo progressivo, assiste-se, nas sociedades denominadas ocidentais, uma reformulação jurídica e legal de amplo alcance, disparada a partir da sensibilização para a condição corporal. Seus efeitos convergem para um reconhecimento social das diferentes formas do corpo vivo e sexual. De modo paralelo, outros aspectos relacionados ao corpo, tais como a alimentação e a qualidade de vida em sua relação com o meio ambiente também se desdobraram em regulamentações jurídicas cada vez mais detalhadas.

\section{CONSIDERAÇÕES FINAIS}

Tal como é possível observar, as formas pelas quais o poder se exerce podem variar, constituindo domínios distintos como o poder disciplinar e a biopolítica. Esta heterogeneidade dos dispositivos, que pode vezes se sobrepõe parcialmente, coopera para invisibilidade do poder, característica essa assinalada por Foucault. Acercandose da vida humana por diferentes vias, o poder se ocupa das potencialidades do sujeito individual, bem como de sua condição de espécie viva. Nesse processo, o poder intervém sobre a sexualidade, que se torna objeto de análise e diagnóstico, 
sempre visando à normalização de suas práticas para que estas se mantenham compatíveis com a ordem social.

Corpo e sexualidade ganharam lugar de destaque no âmbito da política e é nesse contexto que se pode compreender a emergência histórica de políticas públicas centradas na condição corporal. É o caso, por exemplo, da institucionalização de políticas públicas voltadas para a educação sexual, o planejamento familiar, a prevenção da gravidez precoce, dentre outras. No âmbito mais geral, a biopolítica toma como objeto a vida humana para inscrevê-la na lógica da produção, o que proporciona o surgimento de campos do saber tais como a medicina do trabalho, voltada para a manutenção do corpo saudável, assim como as políticas públicas que abordam a questão do uso de drogas, dentre outras. É sempre o corpo que está em questão nesses casos. Deste modo, cabe considerar que os poderes vigentes não só mantém uma intervenção moduladora sobre os corpos como também penetram gradativamente nos diferentes domínios da vida humana, individual e coletiva.

A convergência de dois dispositivos de poder, o disciplinar e a biopolítica, ambos dirigidos ao corpo, tem como efeito uma sensibilização para a condição corporal do humano que ainda está em curso e cujos efeitos estão se fazendo sentir. No que diz respeito às sexualidades, cabe se deter sobre a observação de Foucault, de que o poder irritou-as. É possível considerar que deriva deste processo a ascenção vertiginosa do sexo na política instituída e na vida cotidiana compartilhada. Os movimentos de minorias sexuais ganham visibilidade ao mesmo tempo que multiplicam-se os estudos sobre gênero, faixa etária bem como aqueles que entrecruzam estas determinações corporais: a sexualidade da criança, do adolescente e do idoso.

Vida e morte, num sentido amplo, também estão se tornando foco de uma problematização e de um questionamento crescente. Temáticas como a eutanásia e o suicídio assistido ganham a condição de bandeiras de movimentos sociais. Em torno delas, um contingente crescente de seres humanos constrói um posicionamento político. Se por um lado a morte está em questão, por outro é a própria vida e seus modos que ganha destaque. A alimentação, inerente à condição do vivo, ganha evidência com a constituição de segmentos sociais que se organizam em movimentos pautados por essas temáticas. É o caso do vegetarianismo e dos movimentos que recusam a alimentação transgênica, assim como da produção de alimentos orgânicos, sem o uso de agrotóxicos. Na sua aparente dispersão, estes movimentos repercutem 
a ênfase na condição corporal provocada, por sua vez, pela efetuação das poderes ao longo da história recente nas sociedades capitalistas.

Seguramente, no momento histórico atual, não é possível dimensionar todos os efeitos do biopoder em seu processo de sensibilização para a condição corporal da vida humana. Já é possível assinalar, por outro lado, que a socialização dos corpos, tal como realizada pelo biopoder, desconstruiu definitivamente a privacidade e a intimidade com as quais, desde o advento do capitalismo, o humano se acercava ao olhar para o seu próprio corpo. 


\title{
THE SEXED BODY IN POWER RELATIONS
}

\begin{abstract}
:
In Foucault, the problem of power appears always referred to the materiality of the body, its characteristics and potentialities. With the concept of disciplinary power, he points out a power that individualizes the bodies aiming to make them useful and docile. Foucault also highlights a power that is exercised on the population (biopolitics), which recognizes the collectivity and intervenes on it, specifically about your bodily condition. From this theoretical framework described above, this study aims to analyze the path of increasing politicization of themes connected with the body and sexuality that have gained prominence throughout the 20th century and how these themes were incorporated into the daily debate of the populations, at least partially. From the methodological point of view, it is a qualitative and theoretical study that gathers definitions for the analysis of recurrent presence of body themes in different contexts of contemporaneity. Among the results obtained, we put that the qualifying characteristics of the living human body, such as gender, sexuality and age became the target of a permanent attention, whether in the form of knowledge production about them or even as object of sensitizing awareness that takes the body by its political dimension, thus, inscribing it in institutionalized policies and legislations. As a partial conclusion, it is stated that there is a far-reaching normative and valuation change under way, which has the sexed body as its center.
\end{abstract}

Keywords: Biopolitics. Body. Power. Sexuality. Subjectivity.

\section{EL CUERPO SEXUADO EN LAS RELACIONES DE PODER}

\section{Resumen}

En Foucault, el problema del poder siempre aparece referido a la materialidad del cuerpo, sus características y potencialidades. Con el concepto de poder disciplinario, él señala una vertiente individualizadora del poder, que actúa en los cuerpos con el objetivo de hacerlos dóciles y útiles. Foucault también pone de relieve un poder que se ejerce sobre la población (biopolitica), que reconoce la colectividad e interviene en ella, específicamente acerca de su condición de cuerpo. A partir de los puntos de referencia descritos anteriormente, este estudio pretende analizar el camino de creciente politización de temas relacionados con el cuerpo y la sexualidad que han ganado prominencia durante el siglo XX y que, de modo parcial, fueron incorporados en el debate diario de las poblaciones. Desde el punto de vista metodológico, es un estudio cualitativo y teórico que recoge los datos para el análisis de la presencia recurrente de las temáticas del cuerpo en diferentes contextos de la contemporaneidad. Entre los resultados obtenidos observamos que las características calificadoras del cuerpo humano vivo, tales como género, sexualidad y edad, se tornaran objeto de una atención permanente, sea en la forma de producción de conocimiento sobre las mismas, o aún como un objeto de una sensibilización que toma el cuerpo en su dimensión política, inscribiendo el cuerpo, en las políticas institucionalizadas e en las legislaciones. Como conclusión parcial llegamos a la constatación de que está en curso un cambio normativo y evaluativo de amplio alcance que tiene sobre la cuestión del cuerpo sexuado su eje principal.

Palabras clave: Biopolítica. Cuerpo. Poder. Sexualidad. Subjetividad. 


\section{REFERÊNCIAS}

AGAMBEN, G. Homo Sacer: o poder soberano e a vida nua. Belo Horizonte: Editora UFMG, 2002.

BUTLER, J. Problemas de gênero: feminismo e subversão da identidade. Rio de Janeiro: Civilização Brasileira, 2003.

CALIMAN, L. V. Os bio-diagnósticos na era das cidadanias biológicas. Cadernos de Subjetividade. Ano 9, n. 14. São Paulo: 2012.

CARVALHAES, F. ; MANSANO, S. R. V. Mulheres e lutas políticas: conquistas e limites vividos na segunda metade do século $x x$. Inter. Interdisc. INTERthesis, Florianópolis, v.13, n.2, p. 141-164, 2016.

DONZELOT, J. A Polícia das famílias. Rio de Janeiro: Graal, 1986.

FOUCAULT, M. História da Sexualidade II: O uso dor prazeres. Rio de Janeiro: Edições Graal, 1984.

FOUCAULT, M. História da Sexualidade I: A vontade de saber. Rio de Janeiro: Edições Graal, 1988.

FOUCAULT, M. Ditos e escritos V: Ética, sexualidade, política. Rio de Janeiro: Forense Universitária, 2004.

HARAWAY, D. Saberes localizados: a questão da ciência para o feminismo e privilégio da perspectiva parcial. Cadernos Pagu. Campinas, n. 5, p. 7-41. 1995.

JIMENEZ, L.; ASSIS, D. A. D; NEVES, R. G. Direitos sexuais e reprodutivos de crianças e adolescentes: desafios para as políticas de saúde. Saúde debate, v. 39, n. 107, p. 1092-1104, out-dez, 2015.

LEMOS, F. C. S.; GALINDO, D.; RODRIGUES, R. V.; AGUIAR, K. F. Cidades, corpos medicalizados e o biocapital: o mercado da saúde. Fractal: Revista de Psicologia, v. 28, n. 2, p. 187-194, maio-ago. 2016.

MACHADO, R. Introdução. In: FOUCAULT, Michel. Microfísica do poder. Rio de Janeiro: Edições Graal Ltda. 1996. 
MALUF, A. P.; CARVALHO, P. R. Media y sexualidad: la normalización de las prácticas sexuales contemporáneas. Alternativas en Psicología. n. 39, p. 158-172, feb-jul, 2018.

MANSANO, S. V. M. A respeito do conceito de potência na prática clínica: leituras deleuzianas. Psicologia Argumento, v. 34, n. 84, p. 29-38, 2016.

PELBART, P. P. Vida capital: ensaios de biopolítica. São Paulo: Iluminuras, 2003.

SANT'ANNA, D. B. História da beleza no Brasil. São Paulo: Contexto, 2014.

SILVA, L. B. C. Do dispositivo da sexualidade ao dispositivo da biotecnologia.

Fractal: Revista de Psicologia, v. 27, n. 3, p. 291-300, set.-dez. 2015. 